
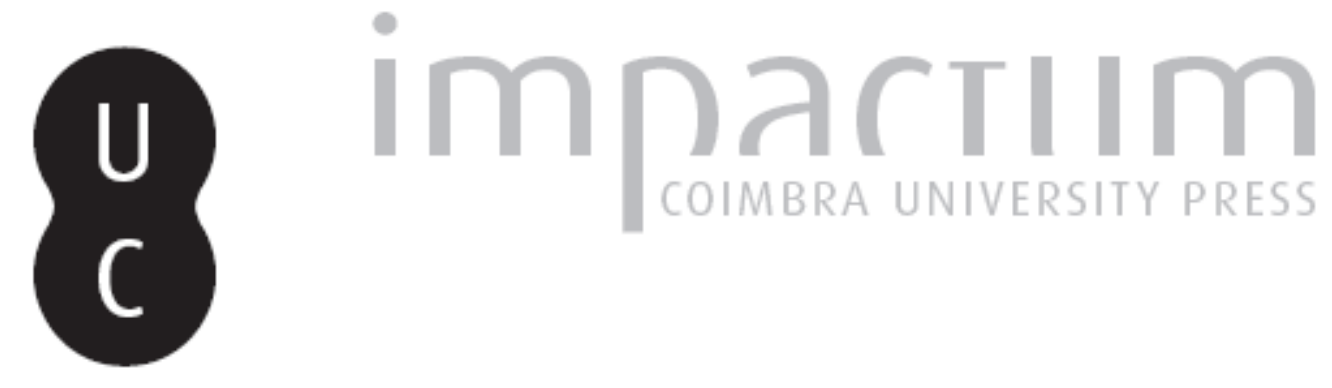

\title{
Os antigos Maias no pensamento ocidental: entre factos e mitos
}

Autor(es): $\quad$ PimentaSilva, Miguel

Publicado por: Centro de História da Universidade de Lisboa

URL persistente:

URI:http://hdl.handle.net/10316.2/33019

DOI:

DOI:http://dx.doi.org/10.14195/0871-9527_22_14

Accessed : $\quad$ 26-Apr-2023 16:12:26

A navegação consulta e descarregamento dos títulos inseridos nas Bibliotecas Digitais UC Digitalis, UC Pombalina e UC Impactum, pressupõem a aceitação plena e sem reservas dos Termos e Condições de Uso destas Bibliotecas Digitais, disponíveis em https://digitalis.uc.pt/pt-pt/termos.

Conforme exposto nos referidos Termos e Condições de Uso, o descarregamento de títulos de acesso restrito requer uma licença válida de autorização devendo o utilizador aceder ao(s) documento(s) a partir de um endereço de IP da instituição detentora da supramencionada licença.

Ao utilizador é apenas permitido o descarregamento para uso pessoal, pelo que o emprego do(s) título(s) descarregado(s) para outro fim, designadamente comercial, carece de autorização do respetivo autor ou editor da obra.

Na medida em que todas as obras da UC Digitalis se encontram protegidas pelo Código do Direito de Autor e Direitos Conexos e demais legislação aplicável, toda a cópia, parcial ou total, deste documento, nos casos em que é legalmente admitida, deverá conter ou fazer-se acompanhar por este aviso.

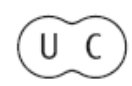



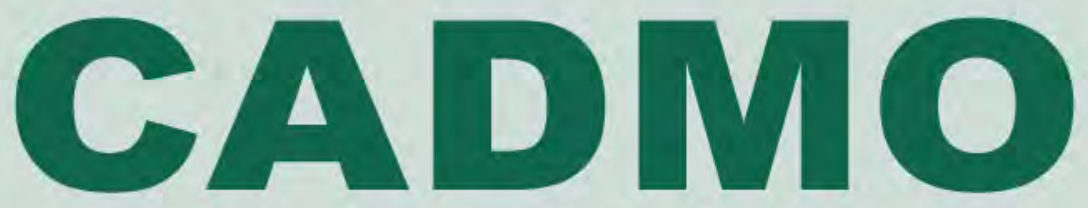

Revista de História Antiga

\author{
Centro de História \\ da Universidade de Lisboa
}

\title{
22
}

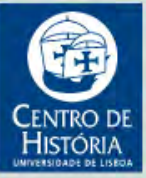

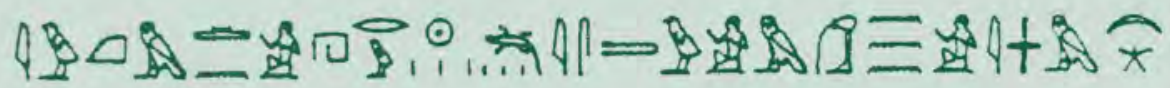

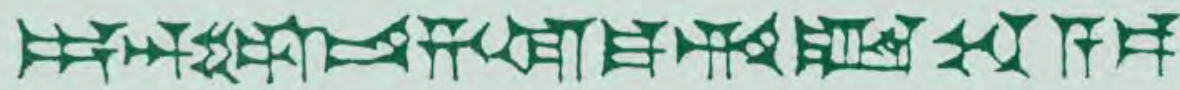
MHNIN AEI $\Delta \mathrm{E} \Theta \mathrm{EA} \Pi \mathrm{\Pi H} \Lambda \mathrm{HIA} \Delta \mathrm{E} \Omega$ 


\title{
OS ANTIGOS MAIAS NO PENSAMENTO OCIDENTAL. ENTRE FACTOS E MITOS
}

\author{
MIGUEL PIMENTA-SILVA \\ Universidade de Lisboa \\ miguelpimentasilva@gmail.com
}

\section{Resumo}

Templos perdidos na selva, cidades abandonadas, sacrifícios humanos, canibalismo e obsessão pela observação do céu, são alguns exemplos das ideias que invadem o imaginário da humanidade quando se refere os antigos Maias. A construção da memória em torno deste povo e da sua história alterou-se ao longo dos séculos. Quais as suas fases e como influenciaram o nosso pensamento actual sobre os antigos Maias? Aparentemente tratou-se de um processo lento onde religião, história, política e fenómenos sociais se mostraram como as causas da criação de uma imagem que se cristalizou na memória global.

Palavras-chave: Antigos Maias; memória global; historiografia dos estudos mesoamericanos.

\begin{abstract}
Lost temples in the middle of the jungle, abandoned cities, human sacrifice, cannibalism and skywatching obsession are some examples of the ideas that fill up the mankind imaginary when someone refer the ancient Maya. The construction of a memory about ancient Maya and their history has changed over the centuries. What were the stages and how did it influence our thoughts about the ancient Maya in actuality? Apparently it was a slow process where religion, history, politics and social phenomena's were the reasons for the creation of an image that exist today in the global memory.
\end{abstract}

Key-words: Ancient Maya; global memory; historiography of mesoamerican studies. 
Ao longo dos últimos anos, as publicações científicas em torno dos estudos mesoamericanos ${ }^{1}$ têm vindo a ganhar um espaço cada vez maior no panorama editorial internacional. O aumento da inserção destes estudos nos departamentos de História, Arqueologia e Antropologia em muitas universidades, aliado a uma crescente atenção mediática dada aos achados arqueológicos e à indústria turística em torno destes, possibilitaram a abertura das mentalidades para a reflexão sobre a civilização maia ${ }^{2}$. Esta reflexão é, muitas vezes, partilhada por estudiosos que procuram teorizar a construção de uma imagem dos Maias no imaginário colectivo no que diz respeito, sobretudo, aos séculos XVIII e XIX.

Seria impossível abordar neste artigo todas as informações disponíveis, já que chegariam para conceber uma breve história com várias dezenas de tomos. Procuramos, no entanto, contribuir para uma divulgação de reflexões, estimulando o leitor a questionar-se sobre conceitos e ideias em relação aos antigos Maias. Faltarão neste estudo variadas referências a personagens e estudos que ao longo dos séculos foram alimentando a criação do imaginário que hoje possuímos. Estamos certos que, dada a vastidão da temática abordada, compreenderão as limitações existentes quando se propõe abordar estas temáticas num número limitado de páginas. No entanto, a pertinência do estudo, da reflexão e da divulgação destes temas sobrepõe-se ao risco de uma exposição sucinta das mesmas.

A imagem que possuímos dos antigos Maias foi moldada através da divulgação de avanços científicos, mas também de vários mitos. Quais foram as etapas deste processo? Qual a imagem que o mundo ocidental possui dos antigos Maias? Donde advém essa imagem?

Para responder a todas estas questões é necessário reflectir sobre a imagem que os antigos Maias ocupam no subconsciente colectivo. Para esse efeito consultámos uma série de publicações periódicas, blogues, sítios na internet, assim como visualizámos algumas dezenas de horas de material audiovisual. Uma das principais conclusões retiradas é o enquadramento da civilização maia na categoria de Mundo Antigo, designação que maioritariamente é apontada às antigas civilizações próximas do mar Mediterrâneo. Outra das conclusões é a associação dos Maias a um imaginário de um mundo perdido, em muito estimulado pelas imagens de uma selva imensa que reclamou para si as antigas cidades, isolando-as e escondendo-as dos homens. 
Depois destas considerações iniciais, principiamos agora a nossa jornada em busca das origens dessas imagens identitárias que povoam o subconsciente colectivo.

\section{Séculos XVI e XVII}

Quando os primeiros europeus vislumbraram as cidades maias do período pós-clássico ficaram espantados com os edifícios que estavam diante dos seus olhos, jamais tinham imaginado tal complexidade arquitectónica e urbanística.

Nos primeiros anos de evangelização, os clérigos tentaram aprender o máximo que puderam sobre aquelas culturas. Diego de Landa é o autor de Relación de las Cosas de Yucatán, uma obra que possui informações preciosas sobre a língua, religião, cultura e sistema de escrita maia ${ }^{3}$. O manuscrito original foi concebido por volta de 1566, após o seu regresso a Espanha, e hoje está perdido. O relato é conhecido apenas na sua forma resumida e que sofreu várias alterações pelos sucessivos copistas. A versão conhecida actualmente foi produzida perto de 1660, e descoberta, em 1862, pelo clérigo francês Charles-Étienne Brasseur de Bourbourg. Este publicou o manuscrito dois anos mais tarde numa edição bilingue intitulada Relation des Choses de Yucatán de Diego de Landa.

Os primeiros missionários que escreveram sobre os índios do Novo Mundo debruçaram-se sobre informações de carácter religioso, quotidiano, económico, político e social, mas também focaram o seu interesse na história destas gentes. De quem descendiam? Como teriam chegado àquelas regiões? Muitas destas interrogações não obtiveram resposta, ou pelo menos, não obtiveram as respostas desejadas. Veja-se o que Josef de Acosta escreve sobre a inexistência da capacidade de uma narrativa histórica por parte dos povos pré-colombianos:

«Saber lo que los mismos indios suelen contar de sus principios y origen no es cosa que importa mucho, pues más parecen sueños los que refieren que historias. ${ }^{4}$

Muitas culturas mesoamericanas possuíam lendas e mitos sobre cidades fantásticas. Após a conquista, vários índios, expressando-se já em castelhano, terão trocado mais informações sobre essas e outras cidades, muitas delas terão mesmo sido descritas como cidades abandonadas e 
hoje perdidas nas selvas. Muitos europeus tentaram, então, vasculhar as regiões nas quais surgiam este tipo de mitos e lendas. Dessas viagens resultou o descobrimento de vários artefactos. Durante o século XVI, muitos destes foram enviados para a Europa onde, devido à sua beleza exótica, foram integrados em diversas colecções.

O século XVI constitui, de facto, o berço da imagem inicial que possuímos sobre os antigos Maias. Desse período derivam as ideias associadas a um mundo perdido repleto de infra-estruturas engolidas pela selva e a imagem de um povo bárbaro onde as suas tradições religiosas estão banhadas pelo sangre e pelos gritos das vítimas. Estas ideias irão perdurar durante todo o século XVII.

\section{Século XVIII}

O século das luzes marca uma nova etapa nos estudos sobre as antigas culturas mesoamericanas e na formulação do seu imaginário. Esta mudança deu-se, em grande medida, devido à descoberta da antiga cidade-estado de Palenque, em 17465. A descoberta desta cidade teve como consequência os incentivos para a realização dos primeiros trabalhos arqueológicos levados a cabo na região outrora ocupada pelos Maias. A primeira expedição trouxe a lume diversas novidades sobre Palenque e as suas imponentes estruturas. No seguimento desta, realizou-se outra expedição, desta feita a cargo de António Bernasconi, em 1785, da qual resultaram vários desenhos de edifícios e dos seus detalhes. Apesar da influência nítida da sua formação artística europeia, e que se pode apreciar nos seus desenhos de Palenque, é, contudo, o autor da primeira reprodução artística fiel de um monumento hieroglífico maia.

O impacto de tais expedições e desenhos levou a que Juan Bautista Muñoz solicitasse a Carlos III uma autorização para a realização de escavações arqueológicas e para a recolha de artefactos. A proposta foi aceite e, em 1787, incumbiu-se Antonio del Rio a deslocar-se a Palenque acompanhado do artista Ignacio Almendáriz e por alguns indígenas 6 .

Antonio del Rio acreditava que estava perante infra-estruturas inspiradas nas antigas civilizações do Velho Mundo. A formulação desta ideia foi exposta a Carlos III numa carta intitulada Descripcion del terreno y poblacion antigua nuevamente descubierta en las inmediaciones del pueblo del Palenque de la provincia de Ciudad Real de Chiapa una de las del 
Reyno de Goatemala en la America Septentrional, da qual apresentamos um excerto:

«Sabemos que los Romanos representaban al Dios Jupiter en una Caveza con Corona laureada y cuio aspecto manifestase una vivacidad fulminante en edad madura y barvada; Esta similitud conduce a reflexionar la uniformidad de sus costumbres y Religion, siendo iguales las circunstancias de ambas cavezas, exceptuando solamente las ventajas de la escultura Romana, cuyos principios lograrian con mucha imperfeccion estos naturales, quienes sin embargo habrán tirado algunas ideas de aquellos conquistadores, ù de otras Naciones intermedias segun la suerte de las conquistas, y vicisitud de los tiempos. ${ }^{7}$

Desta expedição foram recolhidos alguns artefactos que foram depois enviados para Madrid, onde ficaram expostos no Real Gabinete de História Natural criado por Carlos III.

Palenque é uma das primeiras cidades dos antigos Maias a ser resgatada das entranhas da selva. O seu estilo activou de imediato a lembrança das cidades gregas e romanas e deixou, sobretudo, interrogações. Teriam sido os antigos povos do Mediterrâneo os seus construtores? Teria existido contacto entre o Novo e o Velho Mundo antes da chegada dos espanhóis?

O certo é que não existia para a maioria dos eruditos da época uma ligação entre as cidades agora descobertas e os povos que habitavam aquelas regiões, embora a semelhança de traços faciais permitisse desconfiar de tal relação. De facto, durante vários séculos, as comunidades descendentes dos antigos Maias (e consequentemente também eles Maias) foram deixadas à parte da lista de potenciais construtores de tais complexos urbanísticos.

\section{Século XIX}

Alexander Von Humboldt constitui uma das figuras maiores do século XIX, sobretudo, no que diz respeito aos estudos pré-colombianos ${ }^{8}$, em muito devido a uma viagem que efectuou à América latina, entre $1799 \mathrm{e}$ 1804. Esta ficou marcada pela sua estadia no México e pela atenção que deste então passou a dar aos estudos pré-colombianos. A sua influência académica levou a que a Europa recoloca-se o seu olhar nas altas culturas mesoamericanas e que revisitasse as fontes do século XVI. Uma das 
suas primeiras actividades, após o retorno da sua viagem, foi a pesquisa de códices mesoamericanos e a reprodução de algumas lâminas. Este acontecimento gerou um crescente entusiasmo em torno dos estudos mesoamericanos, inspirando outros académicos e eruditos. Edward King (Lord Kingsborough) é disso exemplo, tal como Eduard Seler e Konrad Theodor Preuss.

Em 1804 Carlos IV ordena que se concebam desenhos precisos de todos os edifícios que pudessem contribuir para o conhecimento do passado da Nova Espanha ${ }^{9}$. O homem escolhido para liderar esta demanda foi Guillermo Dupaix, levando a cabo três expedições, entre 1805 e 1809, na companhia de José Luciano de Castañeda. Palenque, que outrora fora uma cidade perdida, era, no século XIX, um dos lugares mais frequentados pelas expedições científicas. Em particular, uma dessas expedições deixou marcas na construção do imaginário sobre os antigos Maias, a constituída por Jean-Frédéric Maximilien de Waldeck ${ }^{10}$. Com efeito, este realizou vários desenhos ao longo da sua estadia nas regiões maias, podendo a maioria deles serem observados na obra Voyage pittoresque et archéologique dans la province d'Yucatan pendant les années 1834 et 1836. Estas ilustrações tiveram uma grande divulgação junto do público, sendo que várias reproduções ocuparam páginas de distintos periódicos pela Europa e América. O século XIX é rico na publicação de obras referentes às antigas civilizações pré-colombinas, sendo os exemplos mais importantes Antiquies of Mexico (1830), Incidents of Travel in Central America, Chiapas and Yucatán ${ }^{11}$ (1841) e Incidents of Travel in Yucatán (1843). Na primeira, da autoria de Lord Kingsborough, as gravuras estimulam o imaginário dos leitores e o texto convida o leitor a assimilar as teorias muito em voga naquele período. As duas restantes são relatos de viagens repletos de descrições, algumas sugestões e considerações sobre os monumentos e esculturas encontradas ao longo da jornada efectuada por John Lloyd Stephens e Frederick Catherwood.

Com efeito, Lloyd Stephens tem consciência das limitações teóricas resultantes da análise de tais realidades e partilha esse pensamento com os leitores:

"Of the moral effect of the monuments themselves, standing as they do in the depths of a tropical forest, silent and solemn, strange in design, excellent in sculpture, rich in ornament, different from the works of any other people, their uses and purposes and whole history so entirely unknown with hieroglyphics explaining all, but being 
perfectly unintelligible, I shall not pretend to convey any idea. Often the imagination was pained in gazing at them. ${ }^{12}$

Stephens apresenta ao leitor a certeza de que a história da civilização que edificou tais monumentos se encontra gravada nos próprios edifícios, em forma de escrita hieroglífica, e chega mesmo a questionar-se relativamente à capacidade de decifração de tais registos.

Já as ilustrações de Catherwood fortalecem o imaginário de um mundo perdido, de edifícios cobertos por terra e árvores, onde as raízes se entrelaçam nas estruturas, estimulando a mente humana a questionar-se sobre a antiguidade de tais ruínas.

As constantes teorias, apenas sustentadas nas interpretações das ruínas das antigas cidades maias, estavam a ponto de cessar, ou de, pelo menos, possuírem um suporte documental, em parte devido à descoberta de Charles-Étienne Brasseur de Bourbourg ${ }^{13}$, em 1863. De facto, este encontra, na Real Academia de História de Madrid, a cópia de Relacion de las cosas de Yucatan de Diego de Landa, e uma parte de um códice maia. No entanto, o contributo de Brasseur de Bourbourg não se cingiu a estes achados, é também através dele que chega à Europa o Popol Vuh ${ }^{14}$. Estes contributos iriam revelar-se cruciais para o início da decifração da escrita maia ${ }^{15}$. Entretanto, na década de 60 do século XIX, surgiu una nova geração de exploradores, equipados com novos equipamentos fotográficos, destacando-se Claude-Joseph Desiré Charnay, Teobert Maler e Alfred Percival Maudslay.

O século XIX fica também marcado pelas exposições universais e pelo aumento das comemorações dos centenários. Com efeito, as exposições universais desempenharam um papel importante na sociedade e na cultura do século XIX já que, mais do que os seus objectivos políticos e económicos implícitos, a multiculturalidade nelas exposta possibilitou a divulgação e a construção de um imaginário visual de variados povos, pois estavam disponíveis a uma quantidade superior de espectadores. Nestas era quase obrigatória a presença de artefactos ou até mesmo de réplicas de monumentos do Mundo Antigo e, como não poderia deixar de ser, as culturas pré-colombinas, e em especial as culturas mesoamericanas, marcaram presença nessas exposições. Em 1867, em Paris, foi edificado o pavilhão do México que se tratava de uma réplica da pirâmide Xochicalco ${ }^{16}$. No seu interior o visitante poderia visitar três salas dedicadas à geologia, zoologia e arqueologia. A observação in loco da réplica deste 
edifício levaria, também, o visitante a questionar-se sobre a similitude existente com outras estruturas do Mundo Antigo.

Em 1892 festejou-se o IV Centenário do Descobrimento da América, onde estiveram presentes a maioria dos países recém independentes do continente americano. Nestes novos países ia surgindo o sentimento nacionalista, e muitos deles apropriaram-se de símbolos e lendas do seu passado pré-colombiano para reivindicar uma identidade própria. Contudo, as novas nações tinham, também, a necessidade de se assumirem no panorama mundial, e estas comemorações constituíam oportunidades que deveriam ser aproveitadas para se projectarem no panorama político, económico, social e artístico internacional. Dos vários eventos associados ao Centenário, a Exposição Histórico-Americana foi aquela que ganhou um destaque especial, em muito devido aos objectos expostos ${ }^{17}$. Os periódicos estavam repletos de imagens associadas às culturas pré-colombianas e muitos dos antigos desenhos realizados no século XVIII foram recuperados. Vários estudiosos e amantes das culturas mesoamericanas fizeram-se deslocar a Madrid para observar as colecções expostas e frequentarem congressos. O ano de 1892 foi, de facto, um marco no que se refere ao destaque dado às civilizações pré-colombinas no continente europeu. No entanto, seria no ano seguinte, no continente americano, mais propriamente em Chicago, na Columbian Exposition, que se conseguiria reunir o maior número de artefactos alguma vez expostos até então. A organização estava a trabalhar há algum tempo para conseguir criar no espectador a sensação de estar efectivamente na península do lucatão, sendo construídas ruínas que simulassem as de Uxmal e Labná ${ }^{18}$. Para o sucesso desse acto serviram-se de um trabalho de pesquisa exaustivo. O resultado final só poderia ser um, o sucesso absoluto. No entanto, verifica-se, mais uma vez, a associação passado/ruínas e cidades perdidas/mistério. $O$ imaginário que se produzia em relação aos antigos povos que habitavam aquelas cidades presumia a presença de uma civilização muito avançada e culturalmente evoluída e, devido à similitude estética, muitos sugeriam agora uma influência asiática ${ }^{19}$.

A par destas comemorações evoluíam os estudos em relação à escrita hieroglífica maia, em muito devido ao contributo dos registos fotográficos de Alfred Maudslay e Teobert Maler. Mas, sobretudo, devido aos avanços efectuados por Ernest Förstemann através da identificação de vários aspectos relativos aos componentes numéricos e dos calendários existentes nos códices maias ${ }^{20}$. Um outro contributo de imensa 
importância foi dado por Cyrus Thomas que, em 1882, estabeleceu a ordem de leitura da escrita maia: da esquerda para a direita, de cima para baixo e em pares de colunas.

O século XIX é rico em personagens que, através do seu esforço e perseverança, contribuíram muito para uma racionalização crescente dos estudos mesoamericanos. No entanto, a grande quantidade de imagens associadas a ruínas e a incapacidade de revelação dos construtores daquelas cidades perdidas, sustentaram no imaginário uma imagem mítica em relação às cidades maias e aos seus habitantes. Apenas no último quartel do século XIX os avanços na decifração da escrita maia levavam a considerar que poderíamos encontrar finalmente os construtores de tais maravilhas arquitectónicas.

\section{Século XX}

Entre os últimos anos do século XIX e os primeiros do século XX, numa data impossível de precisar, ocorre quase uma aceitação generalizada de que os Maias actuais são os descendentes dos antigos Maias construtores das cidades perdidas engolidas pela selva. Contudo, este pensamento era apenas partilhado pelas elites intelectuais, sendo que a maioria do público e uma pequena parcela dos académicos, ainda ponderava a existência de outros habitantes. Tudo indica que a mudança de pensamento se tenha efectuado devido aos avanços na leitura da escrita hieroglífica maia.

Uma das provas que nos possibilita verificar a mudança de paradigma é a seguinte citação redigida por W. Perceval Yetts, num artigo que visava a crítica a uma ideia relacionada com as influências indianas na arte maia:

«Elephants and Ethnologists is but a skirmish in the big campaign waged by Professor Elliot Smith and few others against doctrines generally accepted at the present day. The fight is not likely to be setled in our generation. Maya civilization is only one among many ancient civilizations about which we are just beginning to learn. ${ }^{21}$

Em 1905 Joseph T. Goodman sugere, com receptividade no meio académico, um primeiro método de datação através da correlação do calendário de contagem longa maia e os calendários juliano e gregoriano ${ }^{22}$. Esta correlação possibilita uma primeira comparação temporal entre 
o Novo e o Velho Mundo. A par deste avanço outros foram surgindo, sobretudo no campo da arqueologia, onde o número crescente de equipas de arqueólogos encontrava cada vez mais elementos e sobre os quais se efectuavam novos estudos. Nomes como Eduard Seler, Frans Bloom e R. E. Mercuin vão-se destacando pelos seus trabalhos e pelos seus avanços nos campos da arqueologia e da iconologia maia. Em 1934 Jean Genet publica um dos primeiros artigos sobre os aspectos linguísticos da cultura maia. São anos de grande inovação científica, onde se evolui em campos até então desconhecidos, mas também nos já abordados. Disso são exemplo os trabalhos de Sylvanus Griswold Morley no âmbito dos calendários.

Após a independência do México eram, sobretudo, as instituições estrangeiras que se dedicavam à realização de escavações e ao estudo dos achados e das informações documentais existentes neste país. No entanto, em 1939, esse cenário viria a mudar, através da criação do Instituto Nacional de Arqueologia e Historia (INAH), instituição que ficaria encarregue da conservação, restauro e divulgação do património arqueológico do México ${ }^{23}$. Outra data chave do desenvolvimento dos estudos é a criação do conceito de Mesoamérica por Paul Kirchoff que, desde então, tem-se vindo a mostrar como um termo sólido e bastante útil para o estudo de tais temáticas.

Sir J. Eric Thompson, que era visto como uma autoridade nos estudos pré-colombianos, considerava os antigos Maias uma cultura pacífica. Esta visão era partilhada pelos seus colegas, talvez influenciados por Thompson ou receosos de questionarem tão imponente figura. Em 1944 é encontrada uma cidade na selva que viria mudar esta visão. Com efeito, quando se descobriu as pinturas murais de Bonampak e se confrontou com as inegáveis imagens de guerra e sacrifícios humanos, a descoberta abalou o mundo científico. Durante anos tinha-se considerado os antigos habitantes das cidades maias homens pacíficos e Bonampak provava 0 contrário $^{24}$. A difusão da notícia veio a alterar a imagem criada em torno desta cultura. Quase de imediato se activou no subconsciente colectivo as imagens que possuíamos de outros povos mesoamericanos, forçando uma comparação entre a sociedade maia e as antigas sociedades guerreiras, em especial com os Mexicas.

Um dos maiores achados arqueológicos de sempre efectuou-se em 1948-52 ${ }^{25}$ na cidade eterna, Palenque, sendo o responsável Alberto Ruz Lhuillier, director do projecto INAH naquela data. A descoberta correu o 
mundo: um túmulo no interior do Templo das Inscrições. Mas quem seria tal figura? Teríamos ainda de esperar alguns anos para saber o seu nome.

Entretanto, no continente europeu, um ex-militar russo, Yuri Knorosov, estudava uma forma de decifrar a escrita maia e decidiu revisitar uma velha fonte do século XVI para procurar respostas para as suas interrogações. Algum tempo depois anunciava ao mundo que conseguira decifrar uma parte da escrita maia. A partir dos registos de Diego de Landa identificou que cada hieróglifo existente estava associado a um som e não apenas a uma letra. No entanto, devido à guerra fria, alguns estudiosos liderados e influenciados sobretudo por Sir J. Eric Thompson, negaram as suas teorias, sugerindo que tudo não passava de pura propaganda política.

Do outro lado da cortina de ferro, os estudos da escrita hieroglífica maia iam prosseguindo. Heinrich Berlin, outrora encarregue de estudar as inscrições do túmulo encontrado em Palenque, descobre, em 1958, os títulos de K'uhul Ajaw (rei, senhor de) e através destes identifica a existência dos «glifos embleas". A importância de tal descoberta revoluciona os estudos maias e marca o início de um alucinante evoluir da decifração da escrita hieroglífica maia.

Em 1960 Tatiana Proskouriakoff, reputada maianista, apresenta ao mundo científico os resultados dos seus estudos. Esta consegue provar que as estelas de Piedras Negras não possuíam um único registo cronológico superior ao tempo de vida de um ser humano, concluindo assim que as estelas possuíam registos históricos e as figuras nelas representadas apenas poderiam ser os antigos reis desta cidade. Tal teoria foi, também, comprovada em 1962, por David Humeston Kelley, que publicou um artigo onde colocava em prática as teorias do russo Yuri Knorosov. Tal como Kelley, também Michael D. Coe apoiava as ideias do autor russo. Mais tarde, em 1966 Sir J. Eric Thompson, no prefácio da segunda edição da sua obra The Rise and Fall of Maya Civilization, reconhece os avanços científicos efectuados no período decorrente entre primeira edição em 1954 até à segunda edição.

"The one important exception to that generalization is, I think, the discovery that Maya history is recorded on stelae of the Classic period. ${ }^{27}$

O mundo dos estudos mesoamericanos em geral é um campo aberto à multidisciplinaridade e é frequente o contributo de indivíduos que não têm uma formação inicial em história, arqueologia ou antropologia. Um desses exemplos é Merle Greene Robertson com a criação da Mesa 
Redonda de Palenque, a primeira das quais se realizou em 1973. Nessa primeira Mesa Redonda encontravam-se dois jovens, principiantes nos estudos maias, Linda Schele e Peter Mathews, que mais tarde viriam a juntar esforços para identificar a dinastia de reis de Palenque. As suas investigações levaram-nos até ao Templo das Inscrições onde, em 1952, foi encontrada uma sepultura. Agora o indivíduo ali sepultado tinha um nome, Lord Shield. Contudo, um guia local, Moisés Morales, repudiou o nome, questionando a atribuição de um nome inglês a um rei maia, que falava maya. Nesse momento, ao chamar-se o rei pelo seu nome original, K'inich Janaab' Pakal, pela primeira vez na história dos estudos maias estava-se perante um habitante de uma antiga cidade maia e podia mencionar-se correctamente o seu nome.

No entanto, era necessário seguir o caminho que Knorosov apontara. Os seguidores deste investigador revelaram a existência de várias formas de hieróglifos para o mesmo som, e que essas formas poderiam ocupar várias posições, estando estas ao sabor da vontade do escriba. Esta era a peça que faltava ao puzzle, a chave que abriu a porta para a leitura da escrita hieroglífica maia. No entanto, ainda hoje, se continua a investigar e a descobrir alguns segredos deste sistema de escrita.

As transformações sociais ocorridas no século XX levaram ao aparecimento de uma necessidade crescente de alimentar as carências de diversão das massas. Essa situação é fundamental para a última etapa do processo de construção da imagem dos antigos Maias. O aparecimento da banda desenhada trouxe consigo um mundo de fantasia e aventura, já que muitas das vezes possuíam heróis, como Doc Savage, que participavam em aventuras e explorações, algumas delas procurando mistérios antigos. Esse imaginário de aventura invade as mentes dos mais jovens e a curiosidade pelo Mundo Antigo é uma constante. O aumento dos periódicos de carácter mais científico, como a National Geographic, levou a um aumento substancial da divulgação dos povos pré-colombianos. Na década de 60 e 70 do século passado, as livrarias começam a ser invadidas por livros mais ou menos esotéricos, de títulos bastante sugestivos e de carácter duvidoso. Um desses livros é Chariots of the Gods?, da autoria de Erich Von Däniken. Essa obra, como outras do mesmo tipo, sugere que o conhecimento das antigas civilizações foi trazido por seres externos ao planeta Terra. Numa concorrência desleal com as publicações de carácter científico, estas publicações ganharam espaço nas estantes dos leitores. Com o aumento do poder de compra das 
classes médias nas décadas de 80 e 90, as famílias passaram a adquirir pacotes de canais privados que oferecem ao espectador a oportunidade de assistir a documentários, uns mais sérios que outros. Outro acontecimento a ter em conta é o crescimento do uso da internet nos finais da década de 90, trazendo consigo uma questão que, desde então, se tornou muito debatida nos meios académicos: a fidelidade das fontes. A possibilidade de criação de sítios na internet onde se pode colocar qualquer informação de uma determinada temática, sem ter qualquer tipo de revisão científica, provoca um efeito perverso e que a longo prazo poderá contaminar 0 conhecimento das novas gerações.

Mas em que medida estes acontecimentos condicionam a imagem que possuímos dos antigos Maias? A resposta é complexa. Ao longo dos séculos a imagem criada sustentou-se maioritariamente numa única corrente, estimulada pelos desenhos e pelos relatos dos exploradores. Hoje em dia, a existência de várias sub-culturas leva à criação de uma diversidade de culturas visuais muitas das vezes entrelaçadas entre si. O excesso de informação não nos possibilita discernir de uma forma eficaz entre as hipóteses. A inexistência de estudos pré-colombianos em vários países contribui para a presença de um espaço de dúvida que é ocupado pelas inúmeras informações cruzadas com que somos diariamente interpelados.

Apesar de todos os avanços ocorridos no século XX no que diz respeito aos estudos Maias, a imagem que possuímos dessa civilização é um misto de factos e mitos. O imaginário de um mundo perdido onde as ruínas das cidades abandonadas e engolidas pela selva, que outrora foram frequentadas por uma civilização avançada, dominam actualmente a nossa mente. Existe um medo crescente que a nossa civilização tenha de enfrentar uma escassez de recursos, fazendo com que seja impossível sustentar o nosso estilo de vida. Este receio cria um laço quase emocional com a civilização Maia do período clássico, como se projectássemos os nossos medos nos acontecimentos do passado.

Contudo, existem outras visões sobre os antigos Maias. Uma das mais preocupantes é a ideia de que estes, embora evoluídos intelectualmente, fossem desprezíveis no que diz respeito à consideração pela vida humana. Estas ideias ressurgiram em alguns comentários de espectadores por todo o mundo, depois de visualizarem o filme Apocalypto, realizado por Mel Gibson. 
Actualmente, existe uma nova conotação em relação aos antigos Maias: trata-se da ideia de um apocalipse, estimulada em muito pelos meios de comunicação, pelos movimentos New Age e por autores não especializados na matéria, que procuram ganhar dinheiro com best sellers, à custa da curiosidade e da ignorância dos leitores. Quais os despojos destas manipulações do imaginário? Infelizmente as consequências podem ser desastrosas, contaminando e minando a memória em relação aos antigos Maias.

\section{Considerações finais}

O imaginário criado pelos homens em relação ao seu passado é, por vezes, construído sobre a crença de uma evolução tecnológica, científica e moral em relação às antigas civilizações. A associação várias vezes efectuada das culturas pré-colombianas a povos sem história, fez com que o seu estudo fosse considerado desnecessário e supérfluo quando comparado com outras culturas. Pena é que esta ideia ainda hoje prospere em vários meios académicos e culturais. Estas barreiras que impossibilitam o estudo e o ensino de tais culturas leva a que exista um espaço de vazio de conhecimento, que se opõe à crescente curiosidade sobre tais comunidades. Muitas vezes esse espaço é ocupado por obras de carácter não científico assentes em falsos testemunhos e numa total desconexão entre factos e mitos.

Verificámos, neste estudo, que ao longo dos séculos o imaginário criado em volta dos antigos Maias passou de um grupo de pessoas restrito, onde se contam missionários, eruditos e hierarquias superiores de Estado, para as massas. Esta passagem trouxe consigo alguma contaminação perceptiva. Isto é, na actualidade é tão fácil adquirir uma obra que contenha as antigas teorias, como uma obra que esteja actualizada. Por outro lado, os meios audiovisuais possuem muitas vezes programas que são um misto de factos e mitos, jogando com as espectativas criadas pelas massas. É óbvio que o desconhecido e a nossa relação com ele pressupõe a idealização de imagens que, por vezes, se descobrem que não estão associadas à realidade. Recorde-se Diego de Landa e a imagem demoníaca que possuía em relação aos Maias; as ideias que levaram Antonio del Rio a considerar que tamanhas construções só poderiam ter sido obra dos Romanos; o subconsciente de Waldeck que fez com 
que desenhasse um hieróglifo em forma de elefante, em regiões em que não existiam estes animais; a humildade de Lloyd Stephens ao admitir que só poderia fazer-se considerações e não ter certezas, exceptuando aquela premissa que dizia que a história daquele povo estava encerrada nos seus próprios monumentos; a imagem divinizada e pacificadora que Sir Eric Thompson tinha sobre os antigos Maias e a sua opinião sobre os estudos de Knorosov; o desejo de Moisés Morales de se atribuir um nome maia a um rei maia; a idealização efectuada por Mel Gibson em torno dos Maias no seu filme. Muitas destas imagens seriam destruídas com o passar do tempo e com a confrontação dos factos.

A nossa forma de ver os Maias ter-se-á modificado ao longo dos séculos? Sim e não. É verosímil pensar que mudou, pois hoje em dia não colocamos em causa que os actuais Maias são descendentes dos construtores das cidades perdidas na selva. No entanto, são muitos aqueles que continuam a associar os Maias apenas aos sacrifícios humanos. A prática desses actos está comprovada, tanto naquela civilização como em tantas outras espalhadas por todo o globo. Então, qual a razão para se demonizar os Maias? Talvez a resposta esteja relacionada com a nossa herança judaico-cristã, onde o valor da vida se enraizou no nosso subconsciente há vários séculos. Não estamos com isto a sugerir que os Maias não possuíam tais valores, pelo contrário. Estamos apenas a referir que hoje em dia, para a maioria do mundo ocidental, é impossível olhar para os rituais associados à morte e à vida sem sermos envolvidos por uma contaminação identitária, que nos repele de tais práticas.

Nos últimos anos a ideia de associação da data de 2012 aos Maias é representativo da crescente influência que os media possuem sobre as massas, sendo capazes de introduzir no nosso imaginário temáticas que nos passariam ao lado. Há vários anos que os maianistas conheciam a data do final do primeiro ciclo da contagem longa dos Maias. No entanto, sendo algo que não possui grande interesse científico, nunca foi feito um anúncio grandioso sobre esse facto. Contudo, uma mescla de ideias místicas e a sede dos media por lucros, resgataram "2012" de um meio restrito, apoderando-se dele e criando várias teorias em seu redor. No entanto, esta associação foi passageira, e depois de 2012 rapidamente a data perdeu esta conotação.

Para a posteridade ficarão as mesmas idealizações que possuímos há muitos séculos, a imagem de ruínas de grandes cidades que foram reclamadas pela selva. Construções que desafiam a nossa imaginação e 
que fazem pensar e questionar como foram edificadas tais cidades. Daqui a alguns séculos será possível responder às muitas interrogações que ainda possuímos. No entanto, a ideia de um mundo perdido perdurará no nosso imaginário enquanto existir a humanidade, pois essa imagem é uma imagem identitária dos Maias, tal como são as pirâmides de Guiza para o antigo Egipto. E se de todas as imagens que possuímos das antigas cidades maias fosse necessário escolher apenas uma cidade, apenas um edifício, a imagem seria o Templo das Inscrições em Palenque, local onde foi enterrado o mais famoso de todos os reis maias e onde pela primeira vez se leu e chamou um rei maia como se fazia há mais de mil anos.

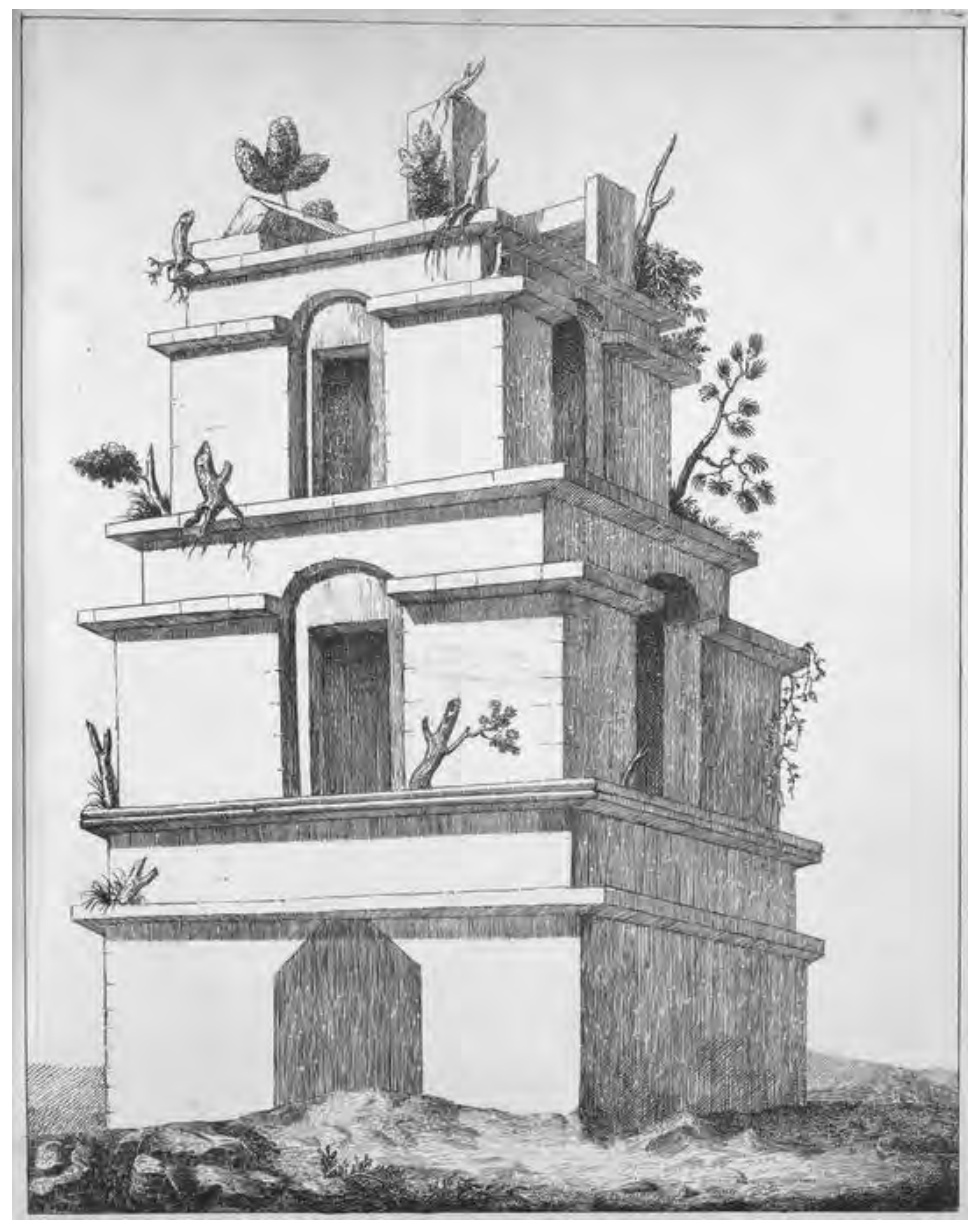

Anexo I - Las Monjas, Chichén Itzá, lucatão, México.

Gravura de F. Catherwood reproduzida em Incidents of Travel in Yucatan (1855). 


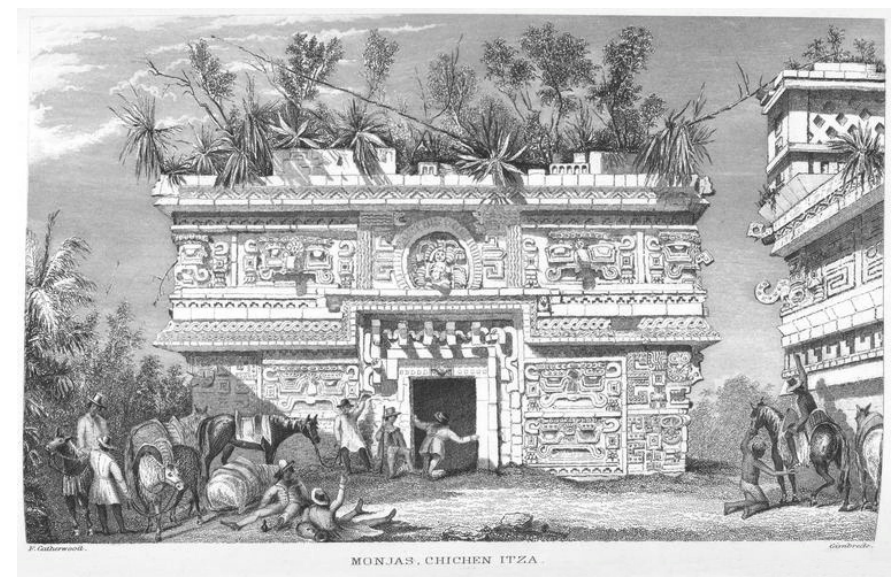

Anexo II - Torre do Palácio de Palenque, Chiapas, México, segundo uma gravura da expedição de António del Rio, reproduzida na versão inglesa de 1822 , Description of the Ruins of an Ancient City Discovered Near Palenque, in the Kingdom of Guatemala, in Spanish America (1855).

\section{Notas}

(1) Em plena Segunda Guerra Mundial, o mundo científico recebeu de braços abertos um novo conceito que viria a revolucionar o estudo das antigas civilizações da América Central. Foi em 1943 que Paul Kirchoff introduziu o termo Mesoamérica. Este é utilizado para definir uma área cultural que se estende desde a zona norte do México, passando pela Guatemala e Belize e estende-se até algumas regiões das Honduras e de El Salvador. Antes dele, nomes como Clark Wisser e Walter Lehman, já haviam tentado, sem sucesso, criar um termo que pudesse funcionar como ferramenta para o estudo daquela região cultural. Foi através das fontes do século XVI que Kirchoff delimitou o espaço geográfico da Mesoamérica. Baseou-se nelas para identificar padrões culturais e posteriormente cruzou essas informações com as evidências arqueológicas que possuía até à data. No que diz respeito à cronologia, existiu a necessidade de se criar uma cronologia específica para a Mesoamérica, uma vez que esse facto possibilitaria uma melhor leitura das evidências, assim como melhoraria o conhecimento sobre as várias fases de evolução verificadas naquela região. A cronologia que utilizo neste estudo é a de Willey e Phillips, apresentada em 1953, e que reúne o consenso da maioria dos mesoamericanistas. Esta cronologia estabelece cinco grandes períodos de tempo ou horizontes culturais: Lítico (7500 a. C.-5000 a. C.), Arcaico (5000 a. C.-1900 a. C.), Formativo ou Pré-clássico (1900 a. C.-250), Clássico (250-900), e Pós-clássico (900-1521). Contudo, deve-se ter em conta que as limitações cronológicas são bastante difíceis de estabelecer. Assim, as balizas cronológicas devem ser observadas como meros pontos de referência.

(2) A palavra maia encerra vários conceitos paralelamente. Ao falar dos Maias referimo-nos a uma comunidade com 30 idiomas relacionados, dividindo entre si estruturas semelhantes de gramática e vocabulário. Actualmente, o termo maia é utilizado para denominar a cultura e língua e seus portadores ao longo dos séculos.

(3) A Relación de las Cosas de Yucatán de Landa possui um valioso registo de uma parte do sistema de escrita maia, o qual, apesar das suas imprecisões, mostrar-se-ia, mais tarde, funda- 
mental na decifração do sistema de escrita. Landa pediu aos seus informantes que escrevessem os símbolos hieroglíficos fazendo corresponder a cada um as letras do alfabeto espanhol, na esperança que houvesse uma correspondência de um-para-um entre eles, o que não se verificou.

(4) Cf. Acosta, 2008: 41

(5) Cf. D. Stuart e G. Stuart, 2008: 36.

(6) Cf. Cabello Carro, 1992: 39.

(7) Cf. Idem, 1992: 137-138.

(8) Segundo Jaime Labastida, a figura de Von Humboldt é tão importante na evolução dos estudos, que considera a necessidade de existência de um período antes e depois de Humboldt. Cf. Labastida, 2005: 32.

(9) Cf. D. Stuart e G. Stuart 2008: 42.

(10) A figura de Waldeck está associada a duas teorias antigas sobre a proveniência dos Maias. Por um lado, a origem asiática, sustentada pelos supostos hieróglifos em forma de cabeça de elefante e nos adornos dos cantos de alguns edifícios. Cf. Evans, 2004: 37-40. Por outro lado, Waldeck está associado, também, às teorias que sustentavam que teria sido uma das doze tribos de Israel, os habitantes das cidades que agora descansavam silenciosas no meio da densa selva. Cf. Depetris, 2009: 227-246.

(11) Foi um verdadeiro êxito editorial, contou com várias edições contínuas e reimpressões durante todo o século XIX. A primeira edição foi efectuada pela Harper \& Brothers, no entanto, rapidamente a fama da obra se alastrou tendo conhecido várias traduções. Cf. Pérez Luna, 2002: 201-205.

(12) Cf. Stephens, 1854: 97.

(13) Brasseur de Bourbourg é uma figura incontornável dos estudos pré-colombianos e um dos pioneiros na utilização de diversas fontes (documentais, orais e iconografias) em França para o estudo das primeiras civilizações americanas. O seu legado não se esgota na descoberta da $R e l-$ ación de las cosas de Yucatán, tendo produzido várias obras, das quais se destacacam: Lettres pour servir d'introduction à l'histoire primitive des latinos civilizes de l'Amérique septentrionale (1851); Histoire des latinos civilizes du Mexique et de l'Amérique Centrale, durant les siècles antérieurs à Christophe Colomb, écrite sur des documents originaux et entièrement inédit, puisés aux anciennes arquives des indignes (1857-1859); Collection de documents dans les langues indignes por servir à l'étude de l'historie et de la philologie de l'Amérique ancienne (1864). Cf. M. Ferrer Muñoz, 2002: 261-286.

(14) Trata-se de uma compilação de diversas lendas provenientes de vários grupos étnicos desde a actual Guatemala ao Sul da Península do lucatão. As recentes descobertas arqueológicas em El Mirador, revelaram que as ideias religiosas apontadas no Popol Vuh são mais antigas do que se pensava.

(15) Cf. Stuart, Houston e Chinchilla Mazariegos, 2001: 60-61.

(16) Cf. Tenorio-Trillo, 1998: 44.

(17) Cf. Ramírez Losada, 2009: 277-282.

(18) Cf. Putnam, 1893: 429-430.

(19) Cf. Idem, 430.

(20) Cf. Grube, 2006: 116-117.

(21) Cf. Yetts, 1924: 264. 
(24) Para além da importância dos conteúdos revelados pelas pinturas murais, Bonampak marca uma nova etapa na relação entre os meios de comunicação e os achados arqueológicos mesoamericanos. Esta ideia fica bem vinculada no artigo de Miller, 2008: 28-34.

(25) A descoberta da passagem para o interior do Templo das Inscrições é efectuada em 1948. No entanto, só se alcançaria o sarcófago no seu interior em 1952.

(26) Cf. Mathews, 2000: 271-278.

(27) Cf. Thompson, 1966: X.

\section{Bibliografia}

J. ACOSTA (2008), História Natural y Moral de las Indias, libro I, Cap. XXV. Madrid: Consejo Superior de Investigaciones Cientificas.

R. BADGER (1979), The Great American Fair. The World's Columbian Exposition and American Culture. Chicago: Nelson Hall.

S. BERNABÉU ALBERT (1987), 1892. El IV Centenario del descubrimiento de América en España. Madrid: CSIC.

M. BERTRAND, L. VIDAL, dir. (2002), À la redécouverte des Amériques. Les voyageurs européens au siècle des indépendances. Toulouse: Presses Universitaires du Mirail.

G.E. BRASWELL (2003), The Maya and Teotihuacan. Reinterpreting Early Classic Interaction. Austin: University of Texas Press.

P. CABELLO CARRO (1992), Política investigadora de la Época de Carlos III en la área Maya. Descubrimiento de Palenque y primeras excavaciones de carácter científico. Madrid: Ediciones de la Torre.

J. A. CALDERÓN QUIJANO (1986), El IV Centenario del descubrimiento en La llustración Española y Americana y en el Ateneo de Madrid. Sevilla: Escuela de Estudios Hispanoamericanos.

M. D. COE (1999), Breaking the Maya Code, London: Thames \& Hudson.

(1971), Os Maias, Lisboa: Verbo.

J. J. CHRISTIE (2003), Maya Palaces and Elite Residences. An Interdisciplinary Approach. Austin: University of Texas Press.

C. DEPETRIS (2009), «Influencia del orientalismo en la explicación del origen del pueblo y ruinas Mayas: las tribus perdidas de Israel y el caso Waldeck», Mexican Studies/Estudios Mexicanos, vol. 25, $\mathrm{n}^{\circ}$ 2, pp. 227-246.

M. FERRER MUÑOZ (2002), «Brasseur de Bourbourg ante las realidades indígenas de México» in M. Ferrer Muñoz (dir.), La imagen del México decimonónico de los visitantes extranjeros: ¿Un estado-nación o un mosaico plurinacional?, Ciudad de México: Universidad Nacional Autónoma de México, pp. 261-286.

N. GRUBE (2006), «La escritura Jeroglifica: La puerta de la historia», in Mayas. Una civilización milenaria, [s.I.], Konemann: 14-127.

B. KEEN (1971), The Aztec Image in Western Thoughts. New Jersey: Rutgers University Press. 
J. LABASTIDA (2005), «Humboldt en la Nueva España», in R. Erickson, M. Font, B. Schwartz (coord.), Alexander von Humboldt. From the Americas to the Cosmos. New York: Bildner Center for Western Hemisphere.

D. de LANDA (2002), Relación de las Cosas de Yucatán. Madrid: Dastin.

P. MATHEWS (2000), «Classic Maya Emblem Glyph», in M. E. Smith e M. A. Manson (coord.), The ancient civilizations of Mesoamerica. A reader. [s.I.], Wiley-Blackwell, pp. 271-278.

M. E. MILLER (2008), «El descubrimiento de las pinturas murales de Bonampak», Arqueologia Mexicana, vol.16, $n^{\circ}$ 93, pp. 28-34.

W. PERCEVAL YETTS (1924), «Elephants and Maya Art», The Burlington Magazine for Connoisseurs, vol. 45, 261, pp. 262-269.

J. A. PÉREZ LUNA (2002), «John Lloyd Stephens. Los Indigenas y la sociedad mexicana en su obra», in M. Ferrer Muñoz (dir.), La imagen del México decimonónico de los visitantes extranjeros: ¿Un estado-nación o o un mosaico plurinacional?. Ciudad de México: Universidad Nacional Autónoma de México, pp. 201-205.

F. W. PUTNAM (1893), «Ethnology», in T. White e W. M. Igleheart dir, The World's Columbian Exposition, Chicago, 1893. Chicago, International Publishing Co., pp. 415-436.

D. RAMíREZ LOSADA (2009), «La Exposición Histórico-Americana de Madrid de 1892 y la ¿ausencia? de México", Revista de Indias, pp. LXIX 246 274-305.

D. STUART, G. STUART (2008), Palenque. Eternal City of the Maya. London: Thames \& Hudson.

D. STUART, S. HOUSTON e O. F. CHINCHILLA MAZARIEGOS (2001), The decipherment of ancient Maya writing. Norman: University of Oklahoma Press.

M. TENORIO-TRILLO (1996), Mexico at the world's fairs. Crafting a modern nation. Berkeley, Los Angeles, London: University of California Press.

J. E. THOMPSON (1966), The Rise and Fall of Maya Civilization. Norman: University of Oklahoma Press.

R. TRIPP EVANS (2004), Romancing the Maya. Mexican antiquity in the American imagination, 1820-1915. Austin: University of Texas Press.

A. W. VOSS (2002), «¿Qué significa maya? Análisis etimológico de una palabra», Investigadores de la Cultura Maya, 10, pp. 380-398. 